Rong-Sheng Qi, Miao Jin*, Bao-Feng Guo, Xin-Gang Liu and Lei Chen

\title{
Hot-Deformation Behavior and Hot-Processing Maps of AISI 410 Martensitic Stainless Steel
}

DOI 10.1515/htmp-2015-0145

Received June 30, 2015; accepted October 3, 2015

\begin{abstract}
The compressive deformation behaviors of 410 martensitic stainless steel were investigated on a Gleeble-1500 thermomechanical simulator, and the experimental stress-strain data were obtained. The measured flow stress was corrected for friction and temperature. A constitutive equation that accounts for the influence of strain was established, and the hot-processing maps at different strain were plotted. The microstructure evolution of the hot-deformation process was studied on the basis of microstructural observations at high temperatures. Phasetransformation experiments on 410 steel were conducted at high temperatures to elucidate the effects of temperature on the delta-ferrite content. The initial forging temperature and optimum process parameters were obtained on the basis of the processing map and the changes in the delta-ferrite content at high temperatures.
\end{abstract}

Keywords: AISI 410 steel, curves correction, constitutive equation, processing maps, delta-ferrite content

\section{Introduction}

AISI 410 martensitic stainless steel is one of the most widely used materials. $\mathrm{Cr}$, as the main nonferrous component of AISI 410 steel, can form a very thin oxide layer that effectively isolates the metal surface from corrosive media and greatly improves the steel's corrosion resistance [1]. It has therefore been widely used in the fabrication of structure components that require high strength, high toughness, and good corrosion resistance such as valves, shafts, and bearings.

Material flow behavior in the process of hot deformation is complex. The hardening and softening

*Corresponding author: Miao Jin, Key Laboratory of Advanced Forging \& Stamping Technology and Science, Yanshan University, Qinhuangdao 066004, Hebei, China, E-mail: jmiaoysu@163.com Rong-Sheng Qi, Bao-Feng Guo, Xin-Gang Liu, Key Laboratory of Advanced Forging \& Stamping Technology and Science, Yanshan University, Qinhuangdao 066004, Hebei, China

Lei Chen, National Engineering Research Center for Equipment and Technology of Cold Strip Rolling, Yanshan University, Qinhuangdao 066004, China mechanisms are under the influence of the deformation temperature and strain rate [2-4]. Research on the hotdeformation behavior of materials is important for optimizing the processing parameters related to the metalforming process [5, 6]. Researchers have previously investigated the hot-deformation behavior of AISI 410 martensitic stainless steel $[7,8]$. However, in these studies, the influence of strain on the steel's high-temperature deformation behavior was ignored in the constitutive modeling based on an Arrhenius-type equation. In fact, the flow stress changes with an increase in the true strain, and any change in flow stress affects the steel's high-temperature deformation behavior [9, 10]. Furthermore, the effects of friction and the deformation heat-induced increases in temperature on the stress-strain curves are usually ignored.

To increase the plastic deformation ability of a metal and reduce the force required to deform it, metals should be deformed at higher temperatures. However, one of the characteristics of AISI 410 stainless steel is its high forging temperature, which makes it susceptible to forge cracking due to the increase in delta-ferrite content. This problem has plagued the heavy forging for AISI 410 steel in actual production processes, which has resulted in a material that is difficult to form and in high rejection rates [11-13]. In this study, we propose a comprehensive constitutive model for AISI 410 stainless steel in which the developed model compensates for the strain; in addition, the deformation characteristics are analyzed on the basis of the hot-processing map technique and the change in the delta-ferrite content.

\section{Materials and experiments}

The specimens for isothermal compression tests were prepared from the AISI 410 bar stock after hot forging. The chemical compositions of the steel used in the experiments are given in Table 1.

The hot-compression tests were performed on a Gleeble-1500 thermomechanical simulator. The samples used in the tests were cylindrical specimens with a diameter and length of $8 \mathrm{~mm}$ and $12 \mathrm{~mm}$, respectively. To decrease the friction effects, a high-temperature lubricant 
Table 1: Main chemical composition of the AISI 410 used in the experiments (mass\%).

\begin{tabular}{lrrrrrrrrrr}
\hline Elements & $\mathbf{C}$ & $\mathbf{S}$ & $\mathbf{M n}$ & $\mathbf{S i}$ & $\mathbf{P}$ & $\mathbf{C r}$ & $\mathbf{N i}$ & $\mathbf{C u}$ & Mo & Al \\
\hline Content & 0.12 & 0.004 & 0.48 & 0.4 & $\leq 0.03$ & 12.3 & 0.42 & 0.04 & 0.06 & 0.029 \\
\hline
\end{tabular}

was applied and tantalum plates were placed at both ends of the specimens. The specimens were heated to the deformation temperature (ranging from $1,000^{\circ} \mathrm{C}$ to $1,200^{\circ} \mathrm{C}$ at $50^{\circ} \mathrm{C}$ intervals) at a heating rate of $10^{\circ} \mathrm{C} \cdot \mathrm{s}^{-1}$, maintained at the deformation temperature for $5 \mathrm{~min}$, and then subjected to compressive deformation at different strain rates. The strain rates used were $0.1,0.5,1,5$, and $10 \mathrm{~s}^{-1}$, and the deformation value was $60 \%$; specifically, the true strain was 0.9. After the compression test, each specimen was immediately quenched in water, and the time from unloading to reaching the ambient temperature is less than 1 minute. The quenched samples were cut longitudinally and then polished and etched for observation.

The samples used in the heat-treatment tests were cuboidal specimens with both length and width of $15 \mathrm{~mm}$ and a height of $10 \mathrm{~mm}$. The specimens were heated to the experimental temperature (ranging from $1,100^{\circ} \mathrm{C}$ to $1,220^{\circ} \mathrm{C}$ at $20^{\circ} \mathrm{C}$ intervals) in an electric furnace and maintained at the experimental temperature for $1 \mathrm{~h}$. The specimens were then immediately quenched in water. The quenched samples were polished and etched for observation. Five photographs were taken for each specimen under different conditions. The statistical delta-ferrite content was determined from the photographs using image processing software, and the average values from the five photographs of each sample were calculated.

\section{Results}

\section{Friction correction}

In practice, although tantalum plates were used to reduce the friction, the influence of friction between the specimen and the dies increases with an increasing deformation degree. Therefore, the measured flow stress should be corrected by considering the effects of interfacial friction [14]. A simple representation of a solid compression test is shown in Figure 1. Here, $h$ is the height of the deformed specimen, $R_{\mathrm{M}}$ and $R_{\mathrm{T}}$ are the maximum radius and the top radius of the deformed specimen, respectively, and $h_{0}$ and $R_{0}$ are the initial height and radius, respectively.

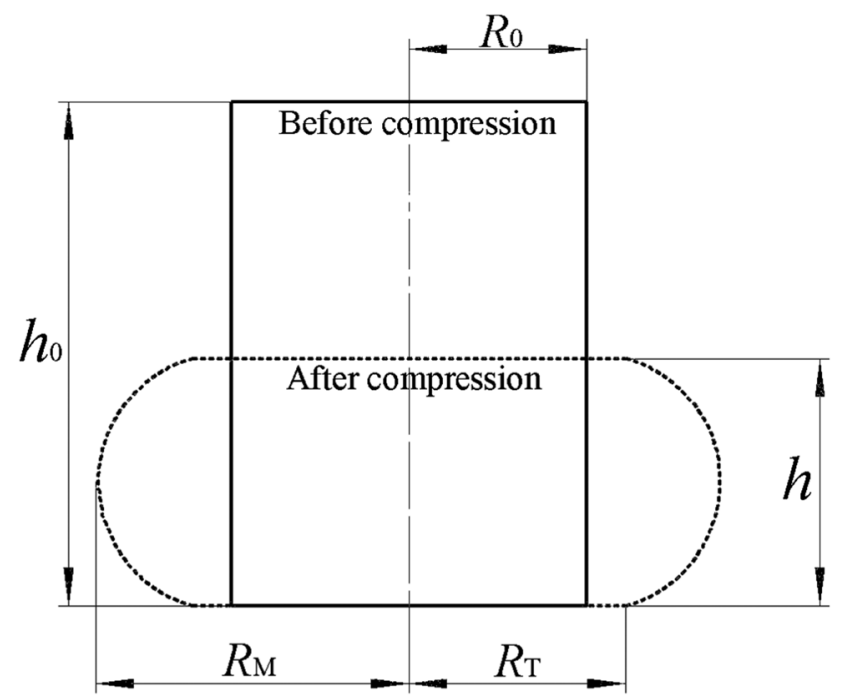

Figure 1: A simple representation of the solid compression test.

To modify the test data, we introduce the correction formula of flow stress [15], which is expressed as follows:

$$
\frac{\sigma_{0}}{\sigma}=\frac{8 b R}{H}\left\{\left[\frac{1}{12}+\left(\frac{H}{R b}\right)^{2}\right]^{3 / 2}-\left(\frac{H}{R b}\right)^{3}-\frac{m e^{-b / 2}}{24 \sqrt{3}\left(e^{-b / 2}-1\right)}\right\}
$$

where $\sigma$ is the corrected true stress, $\sigma_{0}$ is the uncorrected stress (test data); $b$ is the barrel parameter; $R$ and $H$ are the instantaneous values of the radius and height of the sample, respectively, where $R=R_{0} \exp (\varepsilon / 2)$ and $H=h_{0} \exp$ $(-\varepsilon)$; and $m$ is the constant friction factor, which is expressed as

$$
m=\frac{\left(R_{\mathrm{ave}} / h\right) b}{(4 / \sqrt{3})-(2 b / 3 \sqrt{3})}
$$

where $R_{\text {ave }}$ is the average radius of the sample after deformation.

$$
\begin{aligned}
& b=4 \times \frac{R_{\mathrm{M}}-R_{\mathrm{T}}}{R_{\text {ave }}} \times \frac{h}{h_{0}-h} ; \quad R_{\text {ave }}=R_{0} \sqrt{\frac{h_{0}}{h}} ; \\
& R_{\mathrm{T}}=\sqrt{3 \times \frac{h_{0}}{h} \times R_{0}^{2}-2 R_{\mathrm{M}}^{2}}
\end{aligned}
$$

Figure 2 shows the true stress-true strain curves modified to account for the effects of interfacial friction. The measured flow stress is obviously higher than the corrected 

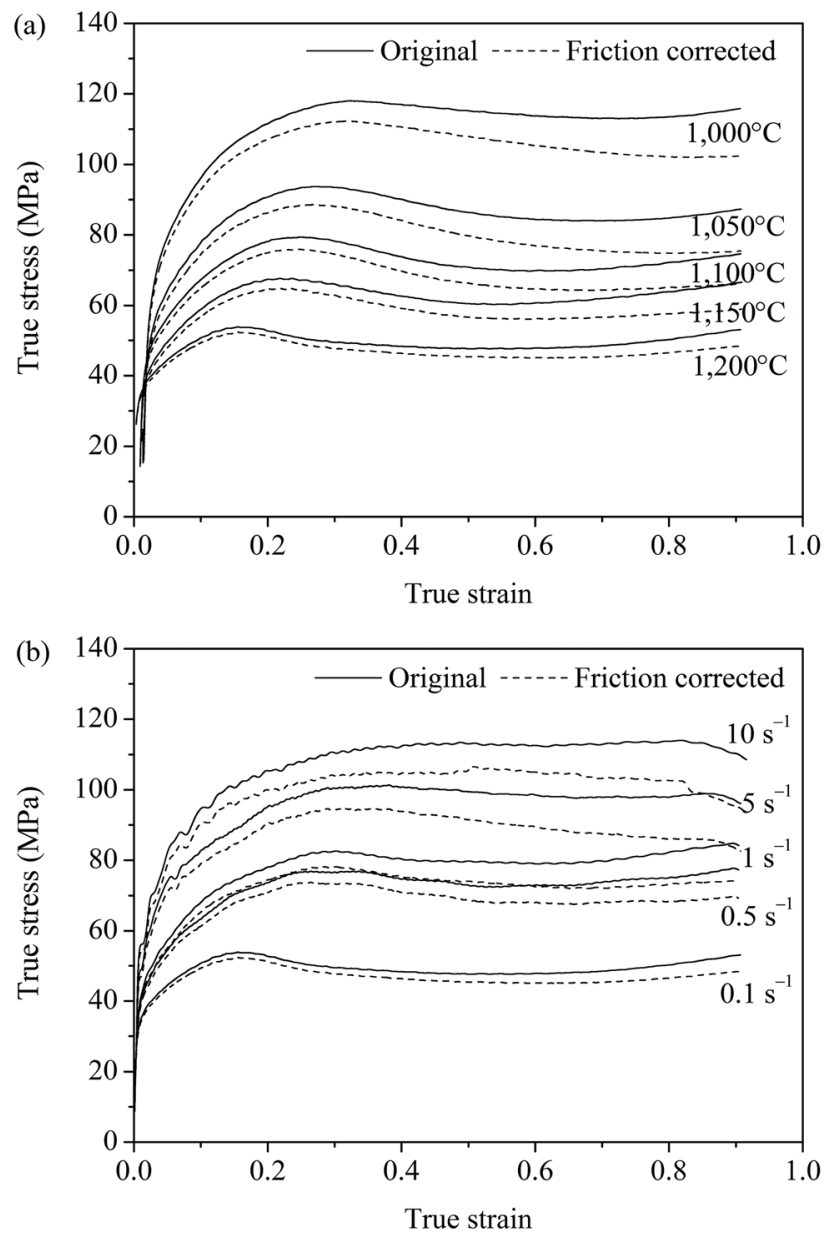

stress-strain curve; $\rho$ is the density $\left(7.75 \mathrm{~g} \cdot \mathrm{cm}^{-3}\right.$ for AISI 410 steel); $C_{\mathrm{p}}$ is the specific heat capacity $\left(0.46 \mathrm{~J} \cdot \mathrm{g}^{-1} \cdot \mathrm{K}^{-1}\right.$ for AISI 410 steel); the factor of 0.95 is the fraction of mechanical work transformed into heat; $\eta$ is the adiabatic correction factor when the strain rate is between $10^{-3} \mathrm{~s}^{-1}$ and $10 \mathrm{~s}^{-1}$ and is typically observed to vary linearly with $\log (\dot{\varepsilon})[16,17]$, i.e., it is equal to $0.5,0.625,0.75,0.875$, and 1 for strain rates of $0.1,0.5,1,5$, and $10 \mathrm{~s}^{-1}$, respectively.

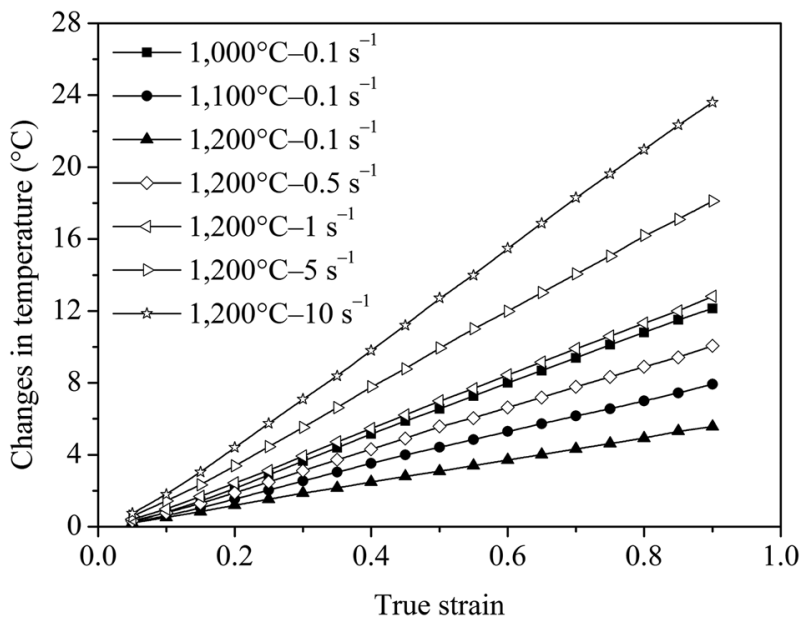

Figure 3: Changes in temperature under different deformation conditions.

Figure 2: Comparison between the friction-corrected and measured flow stresses: (a) $\dot{\varepsilon}=0.1 \mathrm{~s}^{-1}$; (b) $T=1,200^{\circ} \mathrm{C}$.

stress, and with increasing deformation degree, this difference between the measured and corrected stresses increases substantially. The effect of the friction is more obvious at higher strain rates and lower deformation temperatures.

\section{Temperature correction}

Deformation heating occurs in any alloy and is related to strain rate. An increase in specimen temperature during the test is expected to result in a decrease in the measured flow stress compared to the actual flow stress under isothermal conditions. The change in temperature is calculated using the following equation [16]:

$$
\Delta T=\frac{0.95 \eta \int_{0}^{\varepsilon} \sigma d \varepsilon}{\rho C_{\mathrm{p}}}
$$

where $\Delta T$ is the change in temperature; $\int_{0}^{\varepsilon} \sigma d \varepsilon$ is mechanical work, specifically, the area under the uncorrected

Figure 3 shows the changes in temperature under different deformation conditions. The strain rate strongly influences the increase in temperature, i.e., larger strain rates result in greater temperature increases. In addition, the temperature rise decreases with an increasing deformation temperature.

Having determined the actual deformation temperature changes in the tests, we further modified the flow stress curves. The relationships among flow stress, deformation temperature, and strain rate can be expressed by the Arrhenius equation or the exponential equation containing the $Z$ parameter as follows [18-20]:

$$
\begin{gathered}
Z=A_{1} \sigma^{n_{1}}=\dot{\varepsilon} \exp \left(\frac{Q}{R T}\right)(\alpha \sigma<0.8) \\
Z=A_{2} \exp (\beta \sigma)=\dot{\varepsilon} \exp \left(\frac{Q}{R T}\right)(\alpha \sigma>1.2) \\
Z=A[\sinh (\alpha \sigma)]^{n}=\dot{\varepsilon} \exp \left(\frac{Q}{R T}\right) \quad \text { (all levels) }
\end{gathered}
$$

where $\dot{\varepsilon}$ is the strain rate $\left(\mathrm{s}^{-1}\right), \sigma$ is the flow stress (MPa), $Z$ is the Zener-Hollomon parameter, $Q$ is the deformation activation energy $\left(\mathrm{kJ} \cdot \mathrm{mol}^{-1}\right), R$ is the gas constant 
(8.314 $\mathrm{kJ} \cdot \mathrm{mol}^{-1}$ ), $T$ is the deformation temperature (K), $n$ is the strain-hardening exponent, and $A_{1}, A_{2}, A, \beta, n_{1}$, and $\alpha$ are the constants determined by deformation, $\alpha=\beta / n_{1}$.

The flow stress is corrected using eqs (5) and (6) by taking the natural logarithm of both sides. At a given strain value, the curves of $\ln \sigma$ vs. $1,000 / T$ at low strain rates of $0.1 \mathrm{~s}^{-1}$ and $0.5 \mathrm{~s}^{-1}$ and the curves of $\sigma$ vs. 1,000/T at high strain rates of $1 \mathrm{~s}^{-1}, 5 \mathrm{~s}^{-1}$, and $10 \mathrm{~s}^{-1}$ are plotted, as shown in Figure 4. On the basis of the fitting formula of flow stress and temperature, the flow stress for deformation heating is corrected by extrapolating to the preset deformation temperature.
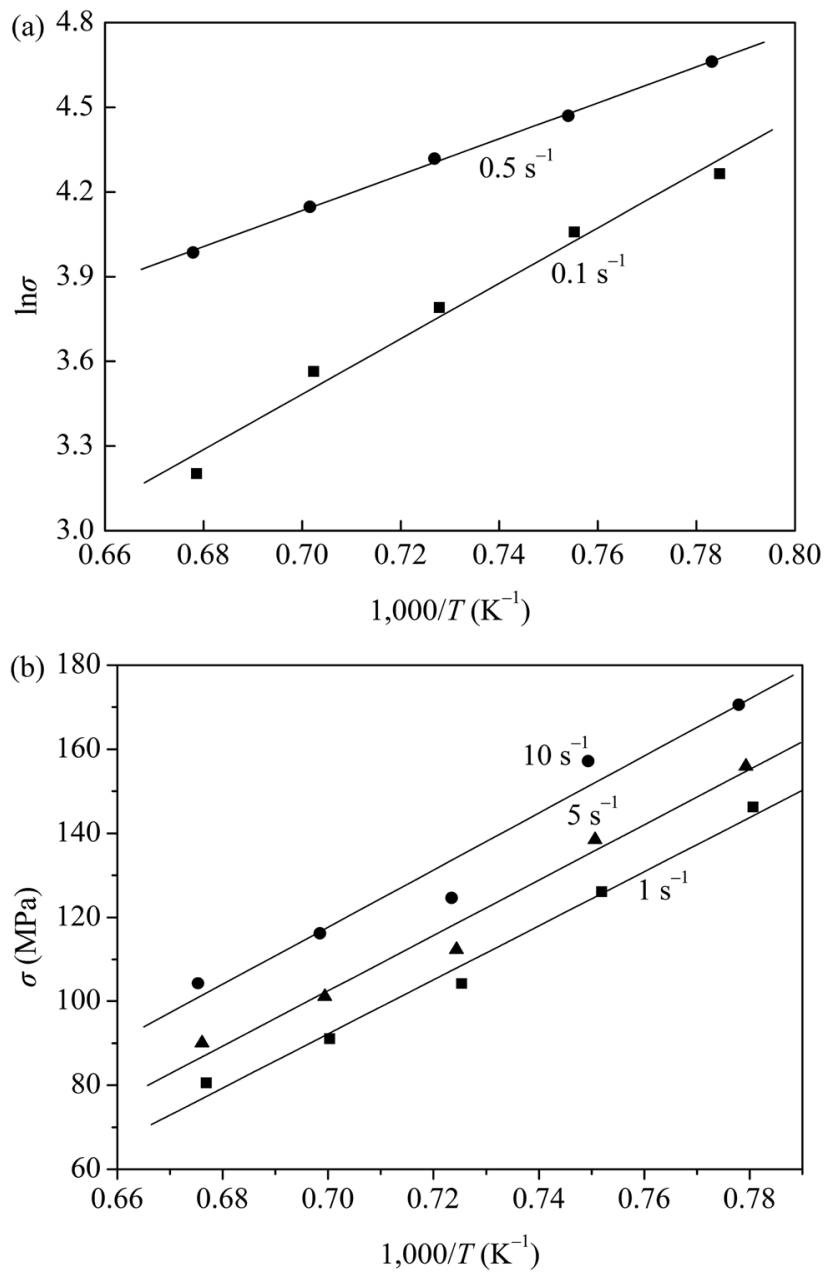

Figure 4: Relationship between $\sigma$ and $T$ at a strain of 0.3 .

Figure 5 shows a comparison between double-corrected stress and single-corrected stress under different experimental conditions. When the strain rate is low, such as $0.1 \mathrm{~s}^{-1}$, the difference between the two curves is small. However, when the strain rate is high, such as $1 \mathrm{~s}^{-1}$ or $5 \mathrm{~s}^{-1}$, the difference is large. At a specific strain rate, the

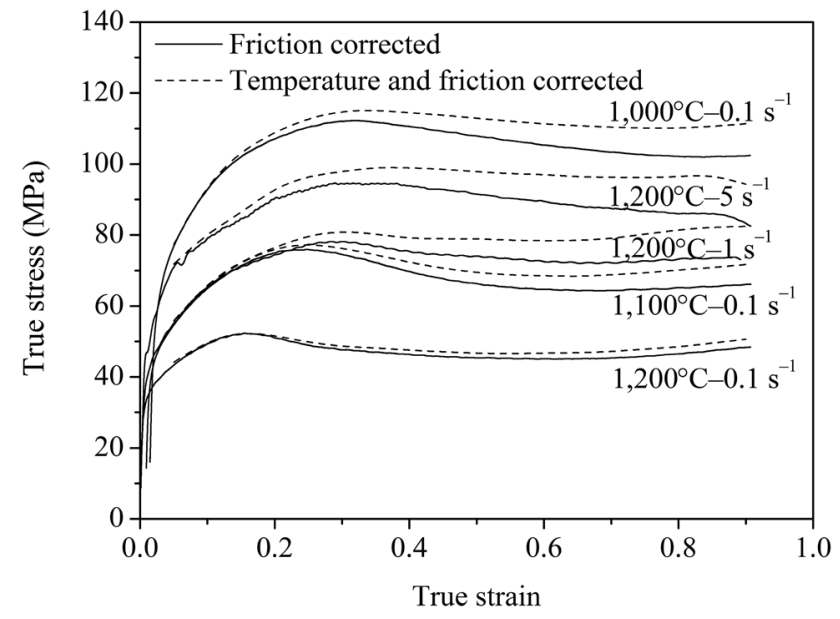

Figure 5: Comparison between the double-corrected and frictioncorrected flow stress.

difference increases with a decreasing deformation temperature.

\section{Flow stress}

Figure 6 shows a comparison between double-corrected and measured flow stress of AISI 410 steel. Under the same deformation conditions and the same deformation degrees, the values of the double-corrected flow stress are smaller than the measured values. These results demonstrate that friction influences flow stress to a greater extent than does the increase in temperature. Under all the experimental conditions, the stress is lower when the deformation temperature is higher and when the strain rate is smaller.

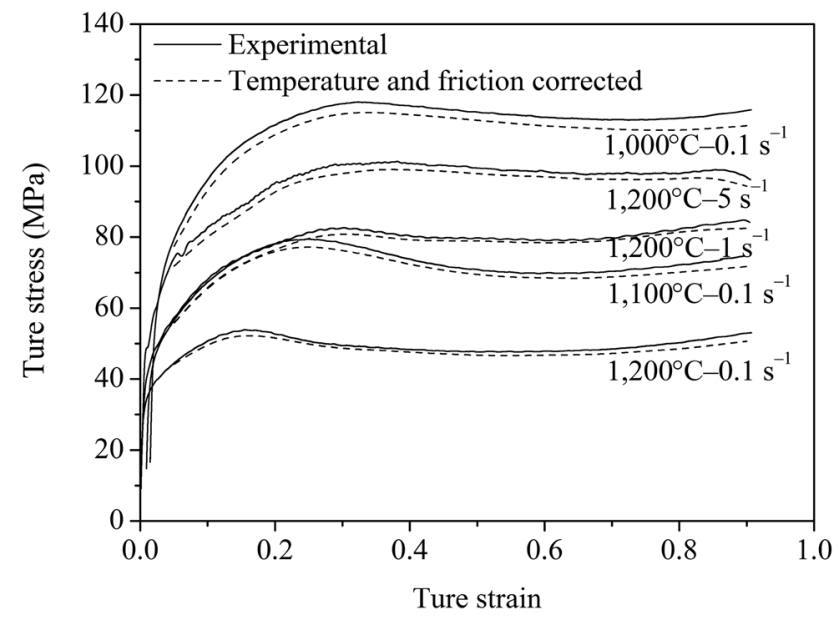

Figure 6: Comparison between the double-corrected and measured flow stress. 
At the beginning of deformation, which is the workhardening period, the stress increases rapidly, as represented by the curves with steep slopes. As the strain increases, the growth of stress slows; correspondingly, the slope of the curve decreases, which is attributed to material softening due to dynamic recovery. During the deformation process, the dislocation density of the samples in which dynamic recovery occurred increases with increasing strain. At the beginning of dynamic recovery, an increase of edge dislocations, the crossslip of screw dislocations, and the annihilation of dislocations lower the dislocation density, resulting in softening [21].

Two types of true stress-strain curves are observed at the end of deformation. In the first type, curves decrease after reaching a maximum and eventually stabilize, as shown in the $1,200^{\circ} \mathrm{C}-0.1 \mathrm{~s}^{-1}$ curve (the curve plotted for data collected at $1,200^{\circ} \mathrm{C}$ and at a strain rate of $0.1 \mathrm{~s}^{-1}$ ). The dominant softening mechanism associated with this type of curve is dynamic recovery plus dynamic recrystallization. Curves of the second type do not exhibit obvious maxima, and the true stress slowly increases with increasing true strain during the deformation process, as shown in the $1,200^{\circ} \mathrm{C}-10 \mathrm{~s}^{-1}$ curve. Curves of this type imply that little or no dynamic recrystallization occurs during the process. The dominant softening mechanism associated with this type of curve is dynamic recovery.

\section{Establishment of the constitutive equations}

\section{Determination of material constants}

Flow stress vs. true strain data from the compression tests performed under various processing conditions were used to evaluate the material constants of the constitutive equations. The following are the evaluation procedures for material constants at a true strain of 0.3. Taking the logarithm of both sides in eqs (5), (6), and (7), respectively, results in the following equations:

$$
\begin{gathered}
\ln \dot{\varepsilon}=n_{1} \ln \sigma+\ln A_{1}-Q / R T \\
\ln \dot{\varepsilon}=\beta \sigma+\ln A_{2}-Q / R T \\
\ln \dot{\varepsilon}=\ln A-Q / R T+n \ln \left[\sinh \left(\alpha \sigma_{\mathrm{p}}\right)\right]
\end{gathered}
$$

At a given strain value of 0.3 , the flow stress value and the corresponding strain rate are substituted into eqs (8)
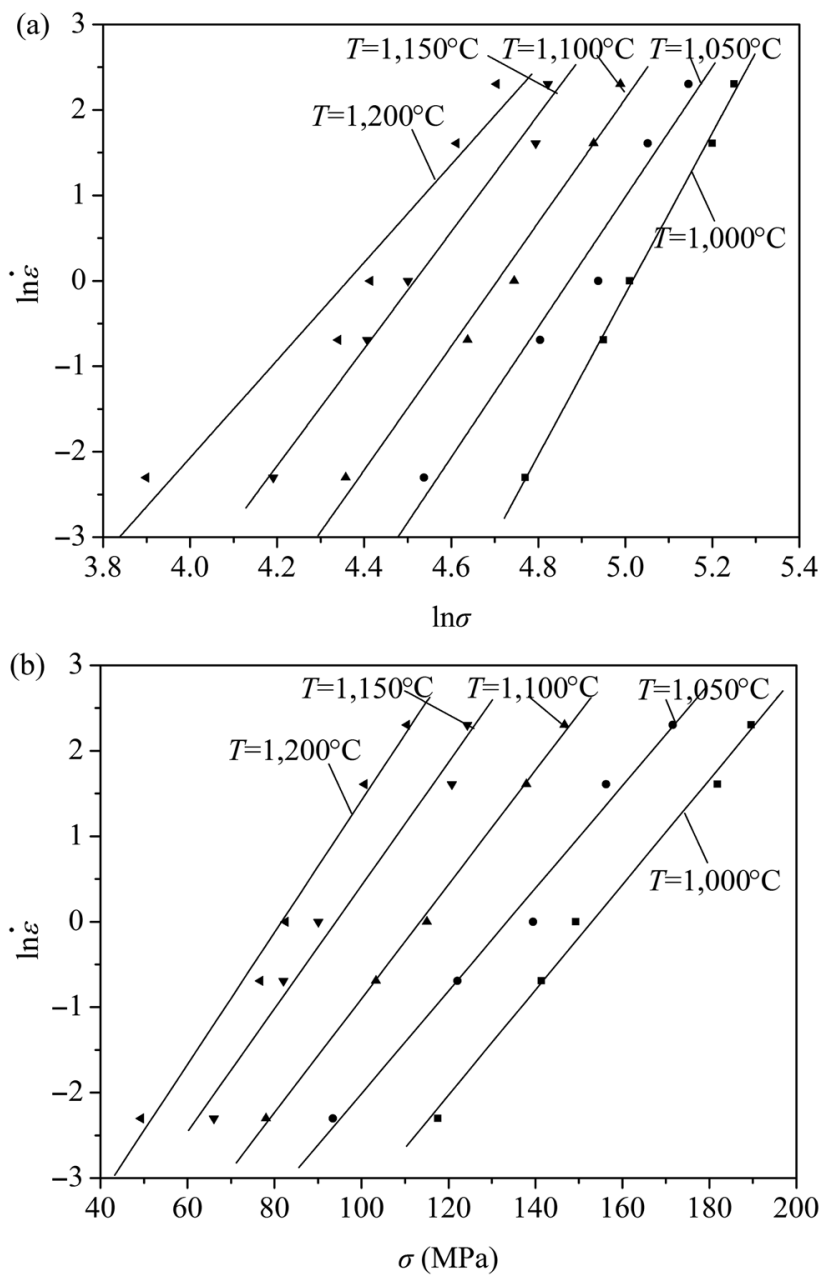

Figure 7: Relationships (a) between $\ln \dot{\varepsilon}$ and $\ln \sigma$ and (b) between $\ln \dot{\varepsilon}$ and $\sigma$.

and (9), and the curves of $\ln \dot{\varepsilon}$ vs. $\ln \sigma$ and $\ln \dot{\varepsilon}$ vs. $\sigma$ are plotted, as shown in Figure 7. The values of slope $n_{1}$ and $\beta$ are obtained by linear regression of each curve. The average values of $n_{1}$ and $\beta$ were calculated as 7.3701 and 0.0676 , respectively. Thus, $\alpha=\beta / n_{1}=0.0092$.

The curve of $\ln \dot{\varepsilon}$ vs. $\ln [\sinh (\alpha \sigma)]$ is plotted according to eq. (10), as shown in Figure 8(a). The slope of the $\ln \dot{\varepsilon}$ vs. $\ln [\sinh (\alpha \sigma)]$ curve gives the value $n$ by linear regression of each curve. The average slope was used to derive the value of $n$, which was 5.4568 . The strain-hardening exponent represents the hardening ability - specifically, the ability of a material to resist plastic deformation. The value of $n$ clearly changed with the deformation temperature; when the temperature increased, the strain-hardening index decreased, indicating that the material is prone to plastic deformation.

For a specified strain rate $\dot{\varepsilon}$, the curve of $\ln [\sinh (\alpha \sigma)]$ vs. $T^{-1}$ is plotted, as shown in Figure 8(b). The slope of 

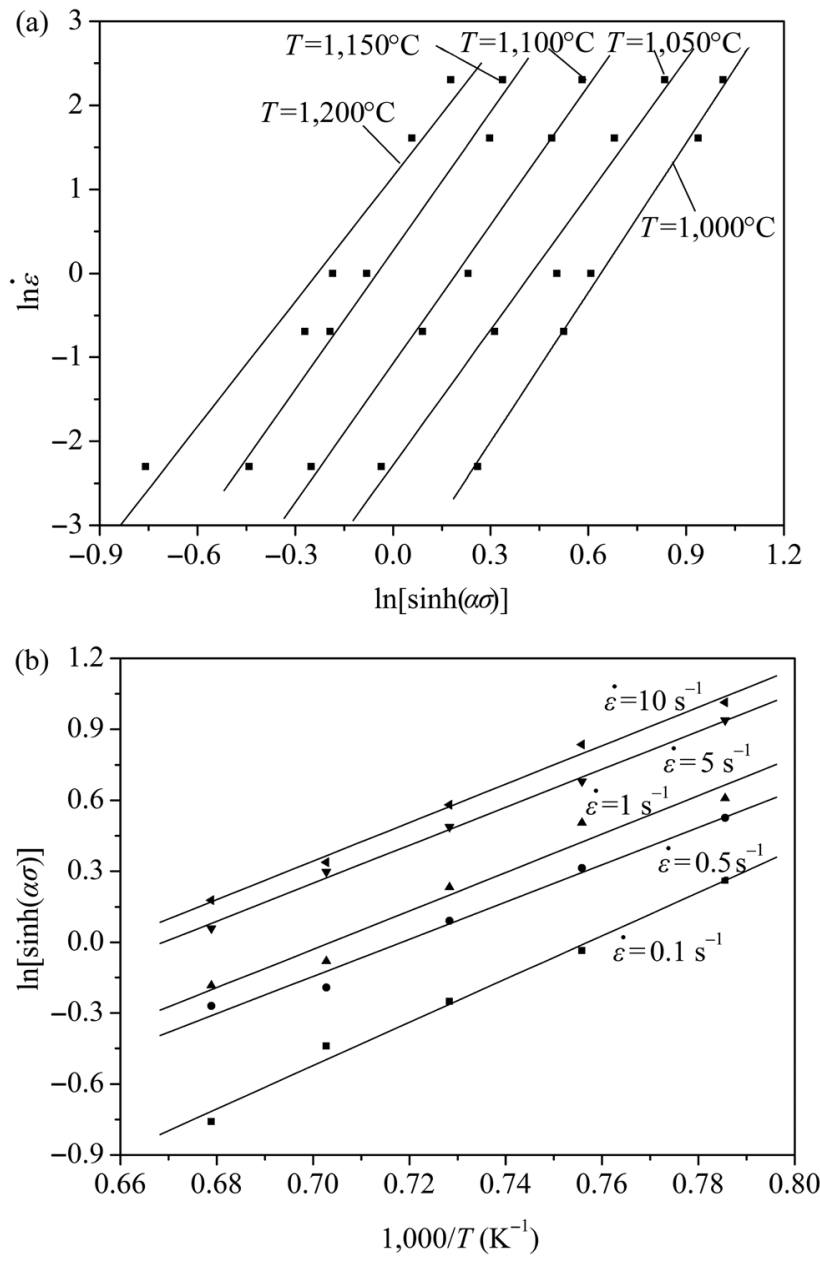

Figure 8: Relationships (a) between $\ln \dot{\varepsilon}$ and $\ln [\sinh (\alpha \sigma)]$ and (b) between $\ln [\sinh (\alpha \sigma)]$ and $1,000 / T$.

the $\ln [\sinh (\alpha \sigma)]$ vs. $T^{-1}$ curve gives the value $Q / R n$ by linear regression of each curve. The average slope was used to derive the value of $Q / R n$, which is 8.2643. By substituting $R=8.314 \mathrm{~J} \cdot \mathrm{mol}^{-1} \cdot \mathrm{K}^{-1}$ and $n=5.4568$ into $Q / R n$, we obtain a value of $374.93 \mathrm{~kJ} \cdot \mathrm{mol}^{-1}$ for $Q$.

By taking logarithms of both sides of eq. (10), we obtain the following equation:

$$
\ln Z=\ln A+n \ln [\sinh (\alpha \sigma)]
$$

From a plot of the curve of $\ln Z$ vs. $\ln [\sinh (\alpha \sigma)]$ (Figure 9), a straight intercept (ln $A=31.8707$ ) is obtained by linear regression. A value of $6.9383 \times 10^{13}$ is then obtained for $A$.

\section{Compensation of strain}

For the compensation of strain, the influence of strain in the constitutive equation is incorporated by assuming

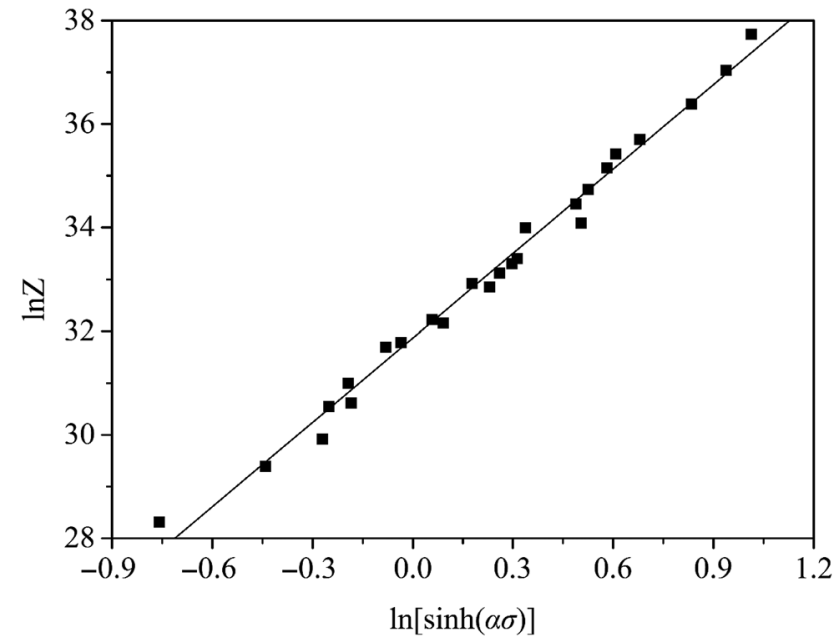

Figure 9: Relationship between $\ln Z$ and $\ln [\sinh (\alpha \sigma)]$.

that the material constants (i.e., $n, \alpha, Q$, and $A$ ) are polynomial functions of strain [22]. The values of material constants of the constitutive equations are computed at various strain levels (in the range 0.05-0.9) at an interval of 0.05 . These values are then used to fit the polynomial. On the basis of the values of the squared correlation coefficients, a unified form of a sixth-order polynomial, as shown in eq. (12), was observed to represent the influence of the strain on material constants with very good correlation for all material constants of AISI 410 steel, as shown in Figure 10. The coefficients of the polynomial are given in Table 2.

$$
\left\{\begin{array}{l}
\alpha=B_{0}+B_{1} \varepsilon+B_{2} \varepsilon^{2}+B_{3} \varepsilon^{3}+B_{4} \varepsilon^{4}+B_{5} \varepsilon^{5}+B_{6} \varepsilon^{6} \\
Q=C_{0}+C_{1} \varepsilon+C_{2} \varepsilon^{2}+C_{3} \varepsilon^{3}+C_{4} \varepsilon^{4}+C_{5} \varepsilon^{5}+C_{6} \varepsilon^{6} \\
\ln A=D_{0}+D_{1} \varepsilon+D_{2} \varepsilon^{2}+D_{3} \varepsilon^{3}+D_{4} \varepsilon^{4}+D_{5} \varepsilon^{5}+D_{6} \varepsilon^{6} \\
n=E_{0}+E_{1} \varepsilon+E_{2} \varepsilon^{2}+E_{3} \varepsilon^{3}+E_{4} \varepsilon^{4}+E_{5} \varepsilon^{5}+E_{6} \varepsilon^{6}
\end{array}\right.
$$

The deformation activation energy $Q$ and strainhardening exponent $n$ of AISI 430, 410, and 420 stainless steels, as reported in the literature, are shown in Table 3; these reported values are typical for martensitic stainless steels. The values of $Q$ vary over the range from 303 to $448 \mathrm{~kJ} \cdot \mathrm{mol}^{-1}$. The AISI 410 deformation activation energy determined in the present study differs from those of both 410 [7] and 410 [23]. As evident in Table 3, the deformation activation energies of 403 [24], 410, and 420 [25] differ substantially. By contrast, the $n$ values of these materials exhibit no obvious differences, ranging from 4.6 to 6.2 .

After the material constants have been evaluated, the flow stress at a particular strain can be predicted. The constitutive equation that relates flow stress and the 

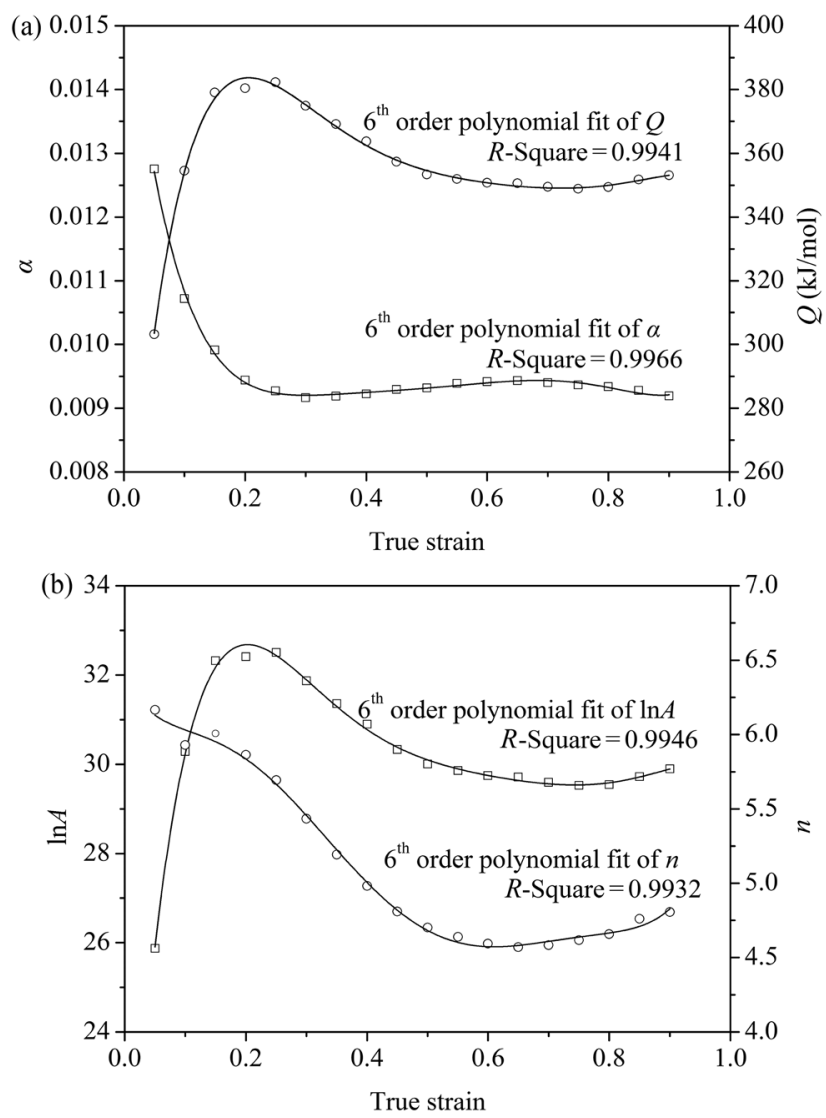

Figure 10: The influence law of strain on material parameters.

Zener-Holloman parameter can be written in the following form:

$$
\begin{aligned}
& \sigma=(1 / \alpha) \ln \left\{\left(\frac{Z}{A}\right)^{1 / n}+\left[\left(\frac{Z}{A}\right)^{2 / n}+1\right]^{1 / 2}\right\} \\
& Z=\dot{\varepsilon} \exp \left(\frac{Q}{R T}\right)
\end{aligned}
$$

\section{Verification of the constitutive equation}

A comparison between the experimental data and those predicted on the basis of the strain-compensated constitutive equation for various processing conditions is shown in Figure 11. As evident in the figure, the predicted data correlate with the experimental results. Deviations are observed only at individual deformation conditions.

To better describe the predictability of the constitutive equation, standard statistical parameters are introduced to quantify the predictability; these parameters include the correlation coefficient $(r)$ and the average absolute relative error (AARE), which are expressed as

$$
\begin{aligned}
r= & \frac{\sum_{i=1}^{n}\left(E_{i}-\bar{E}\right)\left(P_{i}-\bar{P}\right)}{\sqrt{\sum_{i=1}^{n}\left(E_{i}-\bar{E}\right)^{2} \sum_{i=1}^{n}\left(P_{i}-\bar{P}\right)^{2}}} \\
& \operatorname{AARE}(\%)=\frac{1}{n} \sum_{i=1}^{n}\left|\frac{E_{i}-P_{i}}{E_{i}}\right| \times 100
\end{aligned}
$$

where $E$ is the experimental datum, $P$ is the predicted value obtained from the constitutive equation, $\bar{E}$ and $\bar{P}$ are the mean values of $E$ and $P$, respectively, and $n$ is the number of data points used in the investigation.

The correlation between the experimental flow-stress data and those predicted using the constitutive model predicted is shown in Figure 12. A good correlation $(r=0.991)$ was obtained, and the AARE was observed to be $5.62 \%$. These statistical analyses reveal good predictability of the proposed constitutive equation for AISI 410 steel in the temperature range between $1000^{\circ} \mathrm{C}$

\begin{tabular}{|c|c|c|c|c|c|c|c|}
\hline$\alpha$ & & $Q$ & & $\ln A$ & & $n$ & \\
\hline$B_{0}=0.016$ & $\mathrm{~B}_{4}=1.669$ & $C_{0}=209.139$ & $C_{4}=-41,955.056$ & $D_{0}=17.775$ & $D_{4}=-3,701.883$ & $E_{0}=6.360$ & $E_{4}=649.356$ \\
\hline$B_{1}=-0.086$ & $B_{5}=-1.261$ & $C_{1}=2,451.155$ & $C_{5}=28,517.068$ & $D_{1}=211.844$ & $D_{5}=2,515.582$ & $E_{1}=-7.057$ & $E_{5}=-605.754$ \\
\hline$B_{2}=0.435$ & $B_{6}=0.385$ & $C_{2}=-12,779.807$ & $C_{6}=-7,839.279$ & $D_{2}=-1,115.680$ & $D_{6}=-688.442$ & $E_{2}=62.747$ & $E_{6}=210.374$ \\
\hline$B_{3}=-1.148$ & & $C_{3}=31,746.727$ & & $D_{3}=2,790.682$ & & $E_{3}=-310.232$ & \\
\hline
\end{tabular}
and $1200^{\circ} \mathrm{C}$ and under strain rates ranging from $0.1 \mathrm{~s}^{-1}$ to $10 \mathrm{~s}^{-1}$.

Table 2: The coefficients for the polynomial used to model the material parameters of AISI 410 steel.

Table 3: Comparison of $Q$ and $n$ of AISI 410 stainless steel.

\begin{tabular}{lrrr}
\hline Material & Deformation activation energy, $\boldsymbol{Q}(\mathbf{k J} / \mathbf{m o l})$ & Strain-hardening exponent, $\boldsymbol{n}$ & Reference \\
\hline 403 & 395 & 5.4 & {$[24]$} \\
410 & 433 & 5.3 & {$[23]$} \\
410 & 448 & 4.9 & {$[7]$} \\
410 & $303-354$ & $4.6-6.2$ & This study \\
420 & 374 & 5.2 & {$[25]$} \\
\hline
\end{tabular}



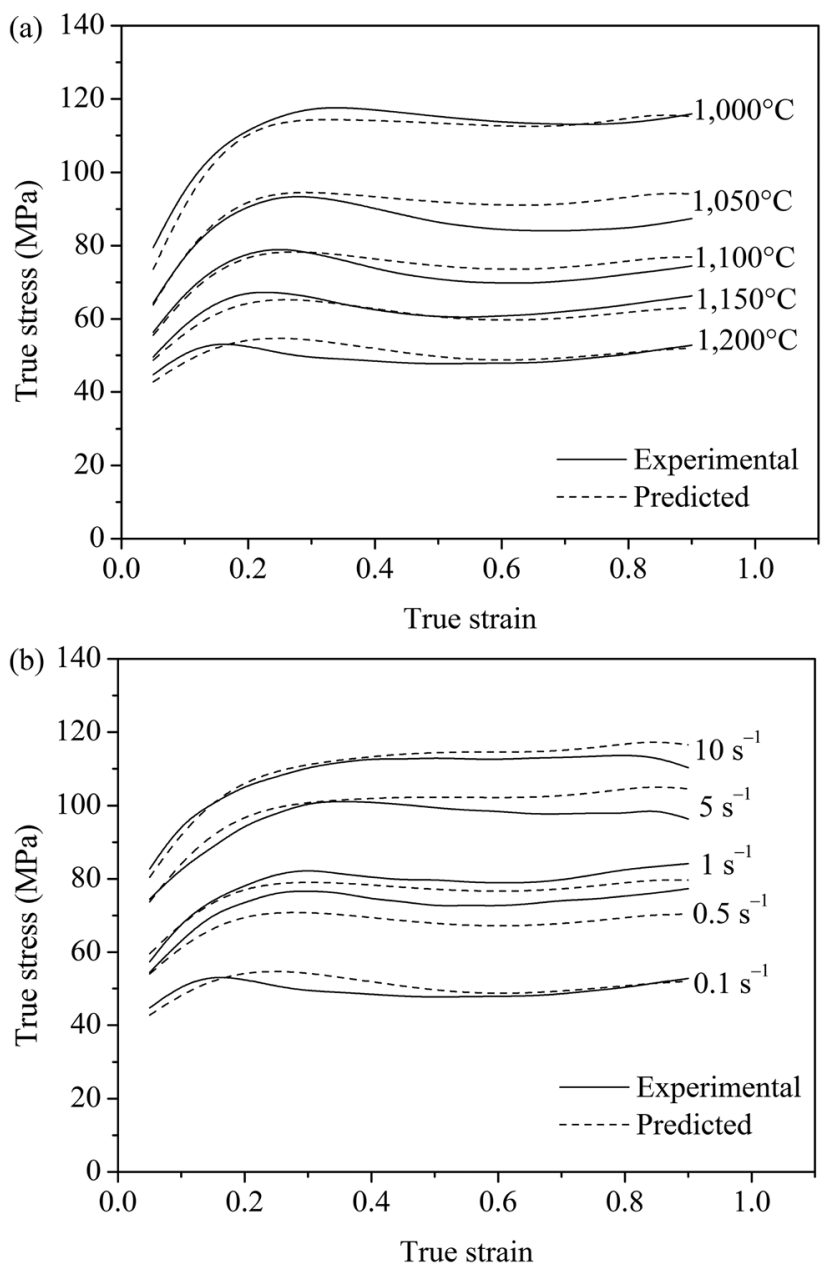

Figure 11: Comparison of the corrected curve and the results predicted by the constitutive equation: (a) $\dot{\varepsilon}=0.1 \mathrm{~s}^{-1}$; (b) $T=1,200^{\circ} \mathrm{C}$.

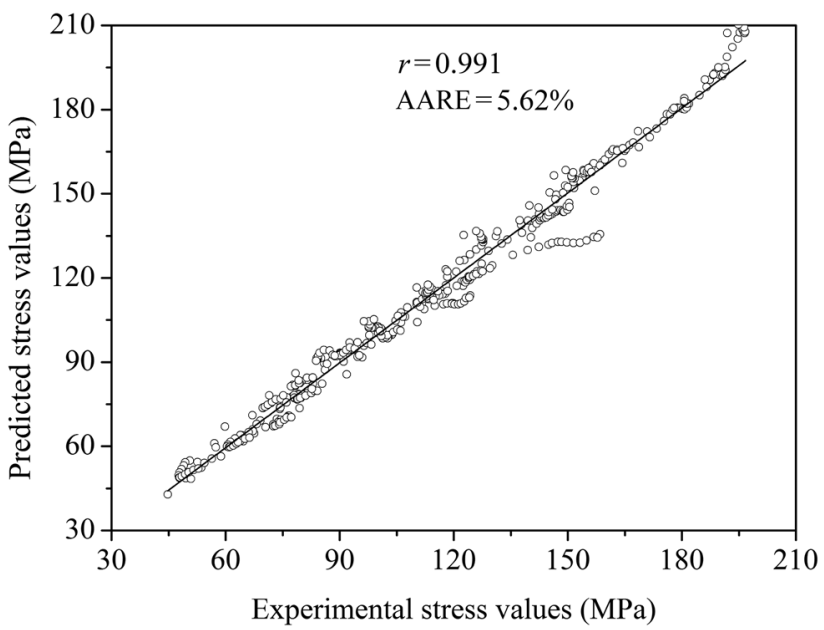

Figure 12: Correlation between the experimental flow-stress data and those predicted using the constitutive model.

\section{Processing map}

A processing map based on the dynamic material model consists of a power dissipation map aimed at introducing the best deformation conditions and an instability map intended to indicate unsafe regions for hot working.

According to dissipative structure theory, the energy per unit volume of a material acquired during hot working is equal to the product of the stress rate and the strain rate $(P=\sigma \dot{\varepsilon})$. However, the dynamic material model maintains that the total power dissipated from the workpiece at any moment consists of two complementary components: dissipation $G$, representing the power dissipated from plastic deformation, and co-dissipation $J$, representing the power dissipated because of microstructure changes. This relationship can be expressed mathematically:

$$
P=\sigma \dot{\varepsilon}=G+J=\int_{0}^{\dot{\varepsilon}} \sigma d \dot{\varepsilon}+\int_{0}^{\sigma} \dot{\varepsilon} d \sigma
$$

According to the dynamic material model, stress can be expressed as $\sigma=K \cdot \dot{\varepsilon}^{m}$. The sensitivity coefficient of strain rate $m$ determines the percentages of $G$ and $J$ :

$$
m=\left[\frac{\partial J}{\partial G}\right]_{\varepsilon, T}=\left[\frac{\dot{\varepsilon} \partial \sigma}{\sigma \partial \dot{\varepsilon}}\right]_{\varepsilon, T}=\left[\frac{\partial(\ln \sigma)}{\partial(\ln \dot{\varepsilon})}\right]_{\varepsilon, T}
$$

Therefore, in the case of ideal linear dissipation, $m=1$ and $J$ is maximal (i.e., $J=G$ ). In the case of nonlinear dissipation, the ratio of co-dissipation $J$ to its maximum $J_{\max }$ is defined as the dissipation efficiency factor $\eta$ :

$$
\eta=\frac{J}{J_{\max }}=m\left(\frac{\sigma \dot{\varepsilon}}{1+m}\right) /\left(\frac{\sigma \dot{\varepsilon}}{2}\right)=\frac{2 m}{1+m}
$$

The non-dimensional power $\eta$ denotes the proportion of power dissipated by microstructure evolution in total power. In general, larger values of $\eta$ indicate more power dissipated by microstructure evolution. A power dissipation map is the contour map indicating that $\eta$ varies with different deformation temperatures and strain rates.

In the process of metal deformation, some deformation mechanisms introduce defects that deleteriously affect the product performance; such defects include internal cracks, wedge-type cracks, voids, and adiabatic shear bands. To avoid these defects, the instability region criterion based on the extremum principles of irreversible thermodynamics applied to large plastic flow, as developed by Prasad and Kumar, is the most widely used criterion [26]. The mathematical expression is

$$
\xi(\dot{\varepsilon})=\frac{\partial \ln \left(\frac{m}{m+1}\right)}{\partial \ln \dot{\varepsilon}}+m<0
$$



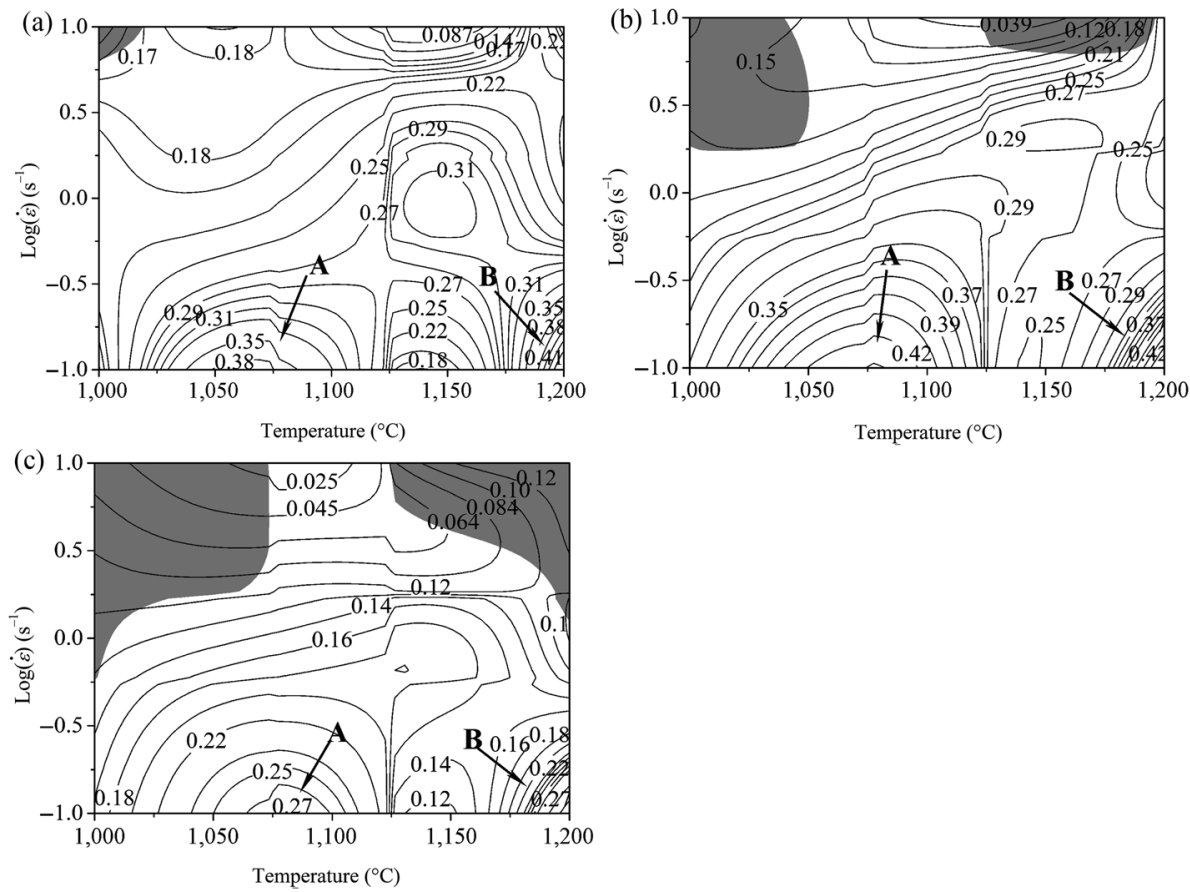

Figure 13: Processing maps of AISI 410 steel with the different true strains: (a) $\varepsilon=0.3$; (b) $\varepsilon=0.6$; and (c) $\varepsilon=0.9$.

Figure 13 shows the processing map for AISI 410 at different true strains, where the black solid curves are the contour lines of power dissipation efficiency $\eta$, whose values are marked on the curves. The shadow represents the instability regions. A small instability region is evident in the processing map at a true strain of 0.3 , which corresponds to the temperature range from $1,000^{\circ} \mathrm{C}$ to $1,020^{\circ} \mathrm{C}$ and a strain rate range of $6.3 \mathrm{~s}^{-1}$ to $10 \mathrm{~s}^{-1}$. The processing map would likely indicate no instability regions when the true strain is less than 0.3. Thus, the steel can be hot worked at low strain without risk of flow instability. When the true strain is increased to 0.6 or 0.9 , the processing maps exhibit two instability regions in each case, and these regions occur in similar positions in the two maps. The scope of the instability regions in the map associated with a strain of 0.9 is obviously larger than that in the map associated with a strain of 0.6.

The strain significantly affects the instability regions, which is evident not only in the scope of each instability region, which increases with increasing strain, but also in the number of instability regions, as demonstrated by other researchers $[27,28]$. These effects of strain explain why internal cracks and wedge-type cracks increase with increasing deformation degree [29]. To prevent the occurrence of the aforementioned microstructure-based defects, which greatly reduce the mechanical properties of steels, the hot-working process should not be performed under conditions that correspond to an instability region. Thus, the processing window of the studied steel becomes smaller with increasing strain.

In addition to the instability regions, stable regions also remain. In general, a larger $\eta$ value for a stability region indicates that a larger proportion of power is consumed by the microstructural evolution. Therefore, a high $\eta$ value is favorable for the hot workability of the materials. Figure 13 shows that two stability regions with high $\eta$ values are present in the processing maps for AISI 410 steel under different true strain conditions. The positions of the two stability regions, marked as A and B in the processing maps, are similar, and such regions are observed in all of the processing maps. Region A exists at a temperature range of $1,050-1,100^{\circ} \mathrm{C}$ and at a strain rate of $0.1-0.2 \mathrm{~s}^{-1}$, with a $\eta$ value range of $0.35-0.43$. Region B exists at a temperature range of $1,180-1,200^{\circ} \mathrm{C}$ and at a strain rate of $0.1-0.2 \mathrm{~s}^{-1}$, with a $\eta$ value range of $0.38-0.56$. The two regions do not overlap with the instability regions, thereby indicating that these regions are suitable for hot working under all strain conditions.

To investigate the change in the microstructure, we examined AISI 410 samples deformed at a true strain of 0.9. The results from four typical samples are shown in Figure 14. Figure 14(a) shows that only dynamic recovery occurred under the deformation conditions of $T=1,000^{\circ} \mathrm{C}$ and $\dot{\varepsilon}=10 \mathrm{~s}^{-1}$. Figure 14(b) and 14(c) indicates that partial dynamic recrystallization occurred under the deformation conditions of $T=1,200^{\circ} \mathrm{C}, \dot{\varepsilon}=10 \mathrm{~s}^{-1}$ and $T=1,050^{\circ} \mathrm{C}$, 

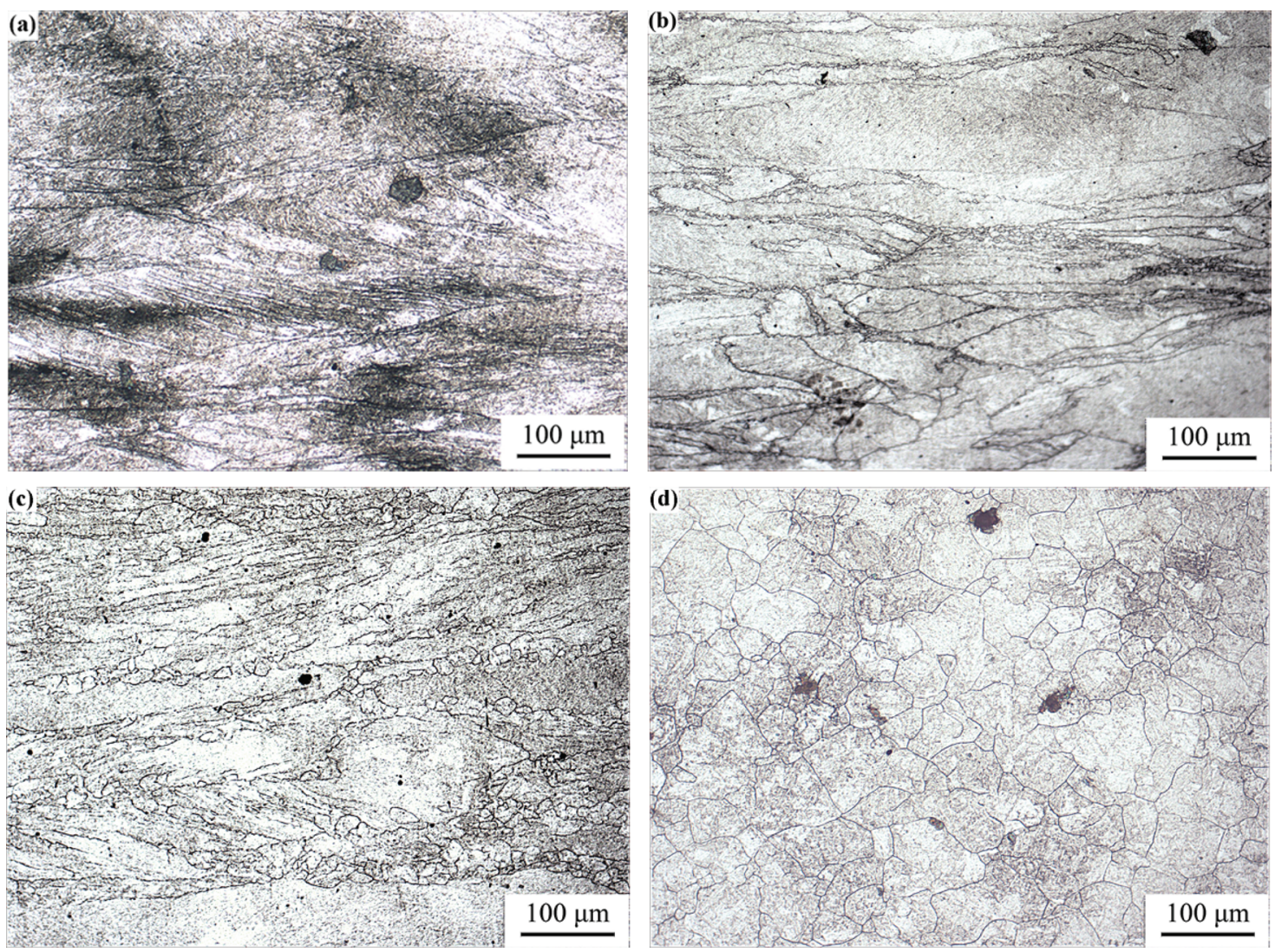

Figure 14: Metallographs showing the microstructure of AISI 410 stainless steel: (a) $1,000^{\circ} \mathrm{C}-10 \mathrm{~s}^{-1}$; (b) $1,200^{\circ} \mathrm{C}-10 \mathrm{~s}^{-1}$; (c) $1,050^{\circ} \mathrm{C}-1 \mathrm{~s}^{-1}$; and (d) $1,200^{\circ} \mathrm{C}-0.1 \mathrm{~s}^{-1}$.

$\dot{\varepsilon}=1 \mathrm{~s}^{-1}$, respectively. In Figure 14(d), a stable dynamic recrystallized microstructure is observed because of complete dynamic recrystallization under the deformation conditions of $T=1,200^{\circ} \mathrm{C}$ and $\dot{\varepsilon}=0.1 \mathrm{~s}^{-1}$. Correction of the measured flow stress can effectively eliminate or reduce the influences of the friction and the deformation heating on the flow stress; furthermore, this correction enables a more accurate determination of the curve type and more reliable predictions of the microstructure evolution.

The flow localization is clearly observed in Figure 14(a) and 14(b), which directly demonstrates the existence of instability in these regions and verifies the accuracy of the constructed processing maps. Partial dynamic recrystallization also occurred - primarily intergranularly and along the deformation bands - in instability regions when the strain reached 0.9. At a deformation temperature and strain rate of $1,200^{\circ} \mathrm{C}$ and $10 \mathrm{~s}^{-1}$, respectively, the dislocation density in the grain boundaries was higher than that in the interior of the grains, thereby facilitating recrystallization nucleation along the grain boundaries. The size of the recrystallized grains was substantially smaller than that of the elongated grains. Finally, a "necklace" structure was formed. With respect to the microstructure in stability regions, partial dynamic recrystallization (Figure 14(c)) or complete dynamic recrystallization (Figure 14(d)) occurred. According to the processing map for a true strain of 0.9 , the $\eta$ value of $1,050^{\circ} \mathrm{C}-1 \mathrm{~s}^{-1}$ is approximately 0.17 , which is slightly larger than that of $1,200^{\circ} \mathrm{C}-10 \mathrm{~s}^{-1}(0.13)$; this slightly larger $\eta$ value for a true strain of 0.9 also indicates that deformation behavior adversely affects the microstructural evolution in the instability regions. The $\eta$ value of $1,200^{\circ} \mathrm{C}-0.1 \mathrm{~s}^{-1}$ is approximately 0.54 , indicating that complete dynamic recrystallization occurred.

\section{Discussion}

To achieve greater plastic deformation ability and reduce the deformation force of AISI 410 stainless steel, it should be deformed at higher temperatures. We also comprehensively analyzed two other important parameters that affect the material forming process: billet heating and 

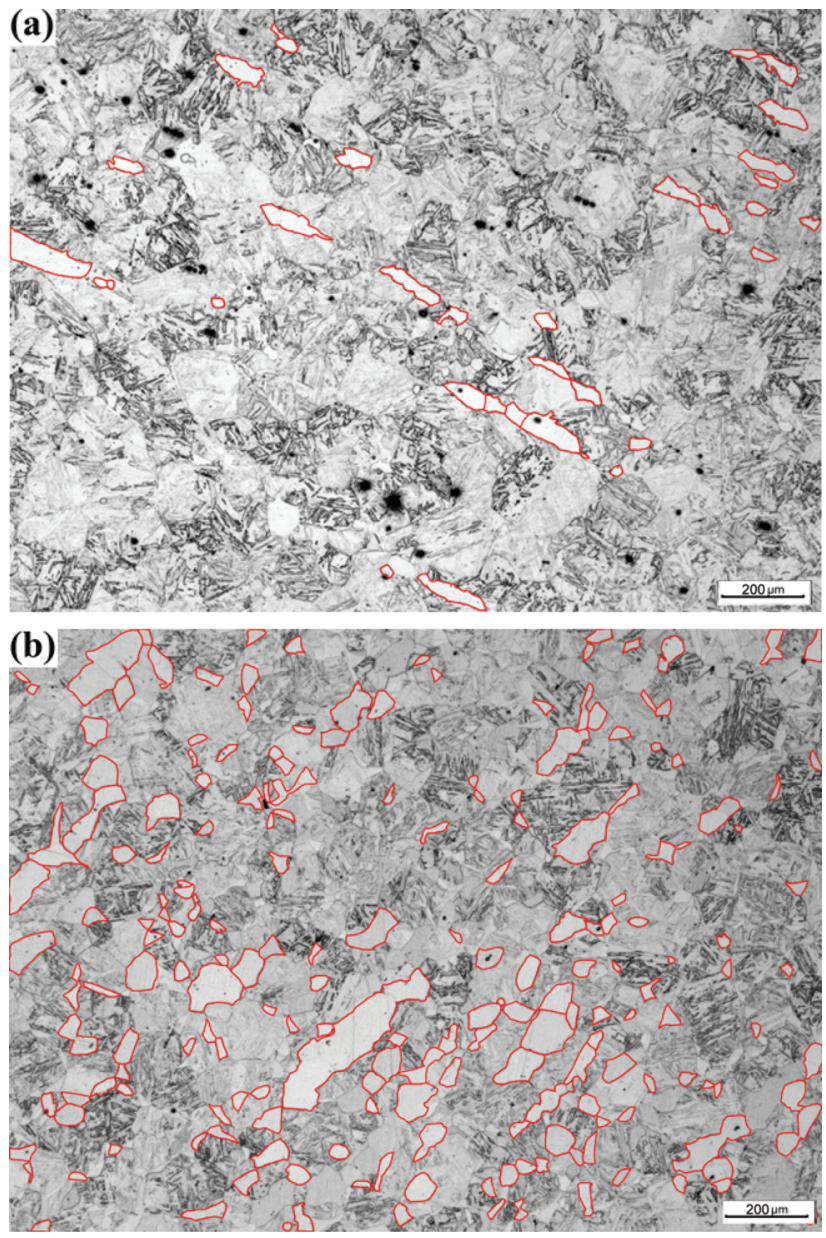

Figure 15: Microstructure of AISI 410 stainless steel at different temperatures: (a) $T=1,100^{\circ} \mathrm{C}$ and (b) $T=1,220^{\circ} \mathrm{C}$ (red-outlined areas indicate typical delta-ferrite grains).

hot deformation. The microstructure photos of AISI 410 stainless steel at different temperatures are shown in Figure 15. Typical delta-ferrite is outlined in red. As shown in the figure, the white-strip delta-ferrite is distributed in the martensitic matrix as a result of quenching organization, where the width of lath martensite is relatively bulky. With increasing temperature of the steel, both the amount and size of delta-ferrite increases.

The statistical content of delta-ferrite was contrastively analyzed using the processing map. The relationship between the percentage of delta-ferrite and the processing map is shown in Figure 16. When the heating temperature was less than $1,140^{\circ} \mathrm{C}$, the delta-ferrite content essentially remained unchanged and was less than $1.6 \%$. As the temperature was increased, the delta-ferrite content increased. The delta-ferrite content was $8.5 \%$ at $1,200^{\circ} \mathrm{C}$ and increased to $13.8 \%$ at $1,220^{\circ} \mathrm{C}$. The positive and negative deviations of the delta-ferrite content were less than $1.2 \%$ under different experimental conditions.

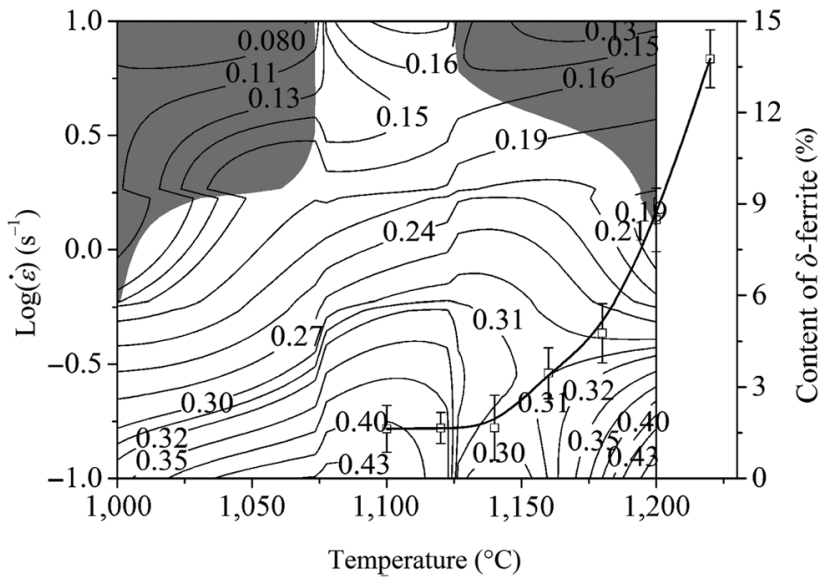

Figure 16: The relationship between the percentage of delta-ferrite and the processing map.

According to the literature [30], AISI 410 stainless steel is most susceptible to cracking when its delta-ferrite content is in the range of $10-30 \%$. Furthermore, the initial forging temperature should not exceed the overheat or overburn temperature. The processing map and the change in the high-temperature delta-ferrite content were comprehensive analyzed for AISI 410 stainless steel. The initial forging temperature should be controlled at $1,200^{\circ} \mathrm{C}$. The optimum process parameters are a deformation temperature of $1,050-1,200^{\circ} \mathrm{C}$ and a strain rate of $0.1-1 \mathrm{~s}^{-1}$.

\section{Conclusions}

(1) The measured flow stress is modified by friction and temperature corrections. Under the experimental conditions for AISI 410 stainless steel, a higher deformation temperature and lower strain rate resulted in lower stress.

(2) The influence of the strain was incorporated into the constitutive analysis by considering the effect of the strain on the material constants, and a sixth-order polynomial was deduced. The predictability of the developed constitutive equation was quantified in terms of $r$ and ARRE, which indicated that the developed strain-compensated constitutive equation provides good prediction capabilities.

(3) The processing maps of the steel at different strains were constructed. Increasing strain led to an expanded instability region, which was located primarily in the high-strain-rate range of $2-10 \mathrm{~s}^{-1}$. Two stability regions with high $\eta$ values were present in similar positions in all of the processing 
maps. Microstructural observations revealed that the deformation conditions strongly influenced the microstructure evolution.

(4) The processing map and the change in the high-temperature delta-ferrite content were comprehensive analyzed for AISI 410 stainless steel. The initial forging temperature should be controlled at $1,200^{\circ} \mathrm{C}$. The optimum process parameters are a deformation temperature of $1,050-1,200^{\circ} \mathrm{C}$ and a strain rate of $0.1-1 \mathrm{~s}^{-1}$.

Funding: This work was supported by the College Innovation Team Leader Training Program of Hebei Province, China (Grant No. LJRC012).

\section{References}

[1] M.C. Tsai, C.S. Chiou, J.S. Du and J.R. Yang, Mater. Sci. Eng. A, 332 (2002) 1-10.

[2] W.J. Dan, W.G. Zhang, S.H. Li and Z.Q. Lin, Comp. Mater. Sci., 40 (2007) 101-107.

[3] C. Sommitsch, R. Sievert, T. Wlanis, B. Günther and V. Wieser, Comp. Mater. Sci., 39 (2007) 55-64.

[4] S. Berbenni, V. Favier and M. Berveiller, Comp. Mater. Sci., 39 (2007) 96-105.

[5] U.S. Dixit, S.N. Joshi and J.P. Davim, Mater. Des., 32 (2011) 3665-3670.

[6] Y.C. Lin and X.M. Chen, Mater. Des., 32 (2011) 1733-1759.

[7] A. Momeni and K. Dehghani, Mater. Sci. Eng. A, 527 (2010) 5467-5473.

[8] A. Momeni and K. DehghaniMet, Met. Mater. Int., 16 (2010) 843-849.

[9] F.A. Slooff, J. Zhou, J. Duszczyk and L. Katgerman, Scripta Mater., 57 (2007) 759-762.

[10] R.S. Qi, B.F. Guo, X.G. Liu and M. Jin, J. Iron Steel Res. Int., 12 (2014) 1116-1123.
[11] J. Qi, Special Steel Technol., 70 (2012) 41-43.

[12] H.S. Li, Special Steel Technol., 49 (2006) 25-27.

[13] Y.Y. Luo and S.T. Li, Heat Treat. Technol. Equip., 4 (2012) 6-11.

[14] R.W. Evans and P.J. Scharning, Mater. Sci. Technol., 17 (2001) 995-1004.

[15] R. Ebrahimi and A. Najafizadeh, J. Mater. Process. Technol., 152 (2004) 136-143.

[16] R.L. Goetz and S.L. Semiatin, J. Mater. Eng. Perform., 10 (2001) 710-717.

[17] P. Dadras and J.F. Thomas Jr, Metall. Trans. A, 12 (1981) 1867-1876.

[18] C.M. Sellars and W.J. Mctegart, Acta Metall., 14 (1966) 1136-1138.

[19] L. Chen, H.Y. Xue, X.C. Ma, M. Jin, H.J. Long, T.Q. Mao and J.F. Wang, Steel Res. Int., 85 (2015) 1-11.

[20] C. Zener and J.H. Hollomon, J. Appl. Phys., 15 (1994) 22-32.

[21] H.J. McQueen and E. Evangelista, Metall. Sci. Technol., 28 (2010) 12-21.

[22] S. Mandal, V. Rakesh, P.V. Sivaprasad, S. Venugopal and K.V. Kasiviswanathan, Mater. Sci. Eng. A, 500 (2009) 114-121.

[23] Y.P. Shi, J.S. Liu and X.W. Duan, Hot Working Technol., 43 (2014) 55-58.

[24] C. Gupta, J.K. Chakravartty, S.L. Wadekar and J.S. Dubey, Mater. Sci. Eng. A, 292 (2000) 49-55.

[25] Y. Cao, H.S. Di, R.D.K. Misra, X. Yi, J.C. Zhang and T.J. Ma, Mater. Sci. Eng. A, 593 (2014) 111-119.

[26] Y. Prasad and S. Sasidhara, Hot Working Guide, A Compendium of Processing Map, Novelty, Materials Park, OH (1997), pp. 312-317.

[27] J. Luo, L. Li and M.Q. Li, Mater. Sci. Eng. A, 606 (2014) 165-174.

[28] Z. Yang, F. Zhang, C. Zheng, M. Zhang, B. Lv and L. Qu, Mater. Des., 66 (2015) 258-266.

[29] Y. Wang, Q.L. Pan, Y.F. Song, C. Li and Z.F. Li, Mater. Des., 51 (2013) 154-160.

[30] X.G. Qian, Y. Huang, L.G. Wang, H. Chen and Y. Fan, Forg. Stamp. Technol., 37 (2012) 70-73. 